\title{
Single and sequential applications of metconazole alone or in mixture with pyraclostrobin to improve Fusarium head blight control and wheat yield in Brazil
}

\author{
Piérri Spolti', Denis S. Guerra ${ }^{2}$, Eliana Badiale-Furlong ${ }^{3}$ \& Emerson M. Del Ponte ${ }^{1}$ \\ ${ }^{1}$ Departamento de Fitossanidade, Faculdade de Agronomia, Universidade Federal do Rio Grande do Sul, 91540-000, \\ Porto Alegre, RS, Brasil; ${ }^{2}$ BASF Corporation, 04538-132, São Paulo, SP, Brasil; ${ }^{3}$ Departamento de Química, Fundação \\ Universidade Federal do Rio Grande, 96201-900, Rio Grande, RS, Brasil
}

Author for correspondence: Emerson M. Del Ponte, e-mail: emerson.delponte@ufrgs.br

\begin{abstract}
Four fungicide trials were conducted in northern RS state during 2009. Six treatments, from the combination of one (flowering = F) or two applications ( F + 10 days) of metconazole sprayed alone or in mixture with pyraclostrobin were tested. Fusarium head blight incidence (INC) and severity (SEV) were assessed at the pre-harvest period and Fusarium-damaged kernel (FDK), kernel infection (KI) and deoxynivalenol (DON) and nivalenol (NIV) trichothecenes were quantified on harvested kernels. Disease incidence ranged from $43.8 \%$ to $90 \%$ and from $7.3 \%$ to $31 \%$ respectively in the unsprayed check. Both INC and SEV were reduced in all fungicide treatments compared to the check across trials. Levels of FDK and KI were not affected by fungicides where susceptible and moderately resistant cultivars were used, respectively. The fungicide $\mathrm{x}$ cultivar susceptibility interaction was significant with the highest severity reduction $(>70 \%)$ susceptible cultivars. Overall yield increased $(+400 \mathrm{~kg} / \mathrm{ha})$ in fungicide-treated plots compared to the check; the mixture of fungicides led to higher increase $(+275 \mathrm{~kg} / \mathrm{ha})$ in yield. Yield increased modestly $(+150 \mathrm{~kg} / \mathrm{ha})$ for two sprays compared to a single spray. Both DON and NIV were found in variable levels across trials but non significant effect of fungicides was found on mycotoxin levels.

Key words: Fusarium graminearum, Gibberella zeae, mycotoxins, strobilurin, triazole.
\end{abstract}

\section{INTRODUCTION}

Fusarium head blight (FHB) is one of the most devastating diseases of wheat worldwide (Goswami and Kistler, 2004). It is mainly caused by Fusarium graminearum sensu lato (teleomorph: Gibberella zeae (Schwein.) Petch) which comprises several biogeographically structured and phylogenetically distinct species (Sarver et al., 2011). In Brazil, $F$. graminearum sensu stricto (hereafter $F$. graminearum), is the most dominant $(>90 \%)$ species of the complex affecting wheat, followed by $F$. meridionale (Astolfi et al., 2012).

Fusarium head blight is of great concern in Brazil due to the high frequency of moderate to severe epidemics that led to significant yield losses since the early 1990s (Del Ponte et al., 2009). In such situations, yield loss is more likely when infections occur during the flowering stage (Goswami and Kistler, 2004), and economic losses related to rejection of grain contaminated with deoxinivalenol mycotoxin (DON) levels above maximum limits are due to a more complex interaction of biological and environmental factors during a larger window that extends from flowering up to grain filling (Cowger et al., 2009; Yoshida and Nakajima, 2010). Published mycotoxin data availabe on Brazilian wheat is scarce but recent reports showed the co-occurrence of DON and nivalenol (NIV) in commercial grain in levels that exceeded $2 \mathrm{ppm}$ according to the year and region surveyed (Del Ponte et al., 2012).

The disease is best controlled with integrated practices such as resistant cultivars and fungicide applications (Hollingsworth et al., 2008; Paul et al., 2008; Wegulo et al., 2011). Although research efforts have effectively enhanced the resistance level to FHB in commercial varieties, host resistance cannot as yet be used solely to control FHB (Mesterhazy et al., 2011). Integrated use of resistant varieties with fungicides effectivelly reduced FHB levels and decreased mycotoxin levels when environmental conditions were favorable for the disease (Wegulo et al., 2011). Triazoles, a class of fungicides in the demethylationinhibiting (DMI) fungicide group that inhibits sterol biosynthesis, are the most efficient fungicides to supress FHB symptoms and reduce mycotoxin levels (Edwards et al., 2001; Paul et al., 2010). Tebuconazole, prothioconazole and metconazole, solely or in mixture of two triazoles, are the most commonly recommended fungicides for FHB control worldwide (Edwards et al., 2001; Pirgozliev et al., 2002; Paul et al., 2008). Strobilurin fungicides, although known to have relatively lower fungitoxicity to FHB pathogens, are commonly used in commercial mixtures together with triazoles to broaden the spectrum of protection against multiple leaf diseases of wheat and eventually lead to higher yield compared to triazole alone, 
especialy under high disease pressure (Blandino et al., 2006; Ransom and McMullen, 2008). Azoxystrobin are not usually recommended for FHB control because of the reports of DON increase, although exhibiting some effect in supressing FHB symptoms (Mesterházy et al., 2003). There is limited information in the literature for other strobilurins such as pyraclostrobin in FHB management (Bradley et al., 2011).

Fungicides targeting FHB are usually applied at the mid-flowering stage because extruded anthers are the primary infection sites, even though the window of vulnerability for infection can extend from flowering up to grain filling stages, depending on the variety (Del Ponte et al., 2007, Horevaj et al., 2011). In North Carolina, United States, fungicide residual period of 10 to 15 days from applications at early flowering were considered sufficient to protect the crop for up to two weeks (Cowger \& Arrellano, 2010). In Brazil, anthesis can last from 10 to 20 days because of the asynchronous nature of heading and flowering depending on the environment (cloudy days extending flowering) and variety (Del Ponte et al., 2004). Such scenario combined with the well known difficulties in promoting good fungicide coverage of the infection sites, suggests that fungicide residual activity alone may be insufficient for effective FHB control when conditons remain favorable from flowering to grain filling stages, especially if the goal is to reduce mycotoxin levels.

Despite the importance and resurgence of FHB as one of the main disease of wheat in Brazil, published data on FHB control with fungicides is very limited in the country. Currently, fungicides are largely used in a preventive way to control foliar diseases and head blight of wheat, especially applying commercial mixtures of triazoles and strobilurins. The information is urgently critical given the inclusion of Fusarium mycotoxins in an updated list of regulated toxins in a broad range of cereal crops, including wheat and barley (Brasil, 2011). Therefore, the objectives of this study were to: 1) evaluate the effect of one versus two sprays of metconazole fungicide applied alone and in mixture with a strobilurin fungicide in supressing FHB and reducing trichothecene mycotoxin levels across different cultivars; 2) determine whether the fungicide effect is influenced by the resistance level of the cultivar.

\section{MATERIALS AND METHODS}

\section{Trial locations and experimental conditions}

Four field trials were conducted during the 2009 growing season. Each of them in a different municipality of Rio Grande do Sul State, Brazil: Cruz Alta [CA (W53³9'59.1" S28 36’39.9”)], Passo Fundo [PF (W52 $\left.\left.21^{\prime} 44.5^{\prime \prime} \mathrm{S}^{\circ} 8^{\circ} 10^{\prime} 51^{\prime \prime}\right)\right]$, Lagoa Vermelha [LV (W51 39'24.3" S28 $\left.\left.8^{\circ} 7^{\prime} 7.6^{\prime \prime}\right)\right]$ and Muitos Capões [MC (W5125'33.2” S28 23 '55.2")].

A single wheat cultivar was used in each trial and they varied according to suceptibility level to FHB. In the
CA and PF trials, Campo Real cv. and BRS Guamirim cv., respectively, were in a moderately resistant (MR) group and in the LV and MC trials, Raízes cv. and Supera cv., respectively, were in the susceptible (S) group. A uniqueness condition of location and cultivar in each trial represented four distinct environments in which the fungicide treatments were evaluated.

The trials were arranged in a randomized complete block design with four replications. The experimental units were $2 \mathrm{~m}$ wide and $5 \mathrm{~m}$ long with a total area of $10 \mathrm{~m}^{2}$ and a row spacing of $0.17 \mathrm{~m}$. During vegetative growth stages the trials were sprayed at 20 (tillering) and 40 (booting) Zadoks growth stages with a commercial mixture (Opera; BASF Corporation) of pyraclostrobin (133 g a.i/L) + epoxiconazol (50 g a.i/L) and insecticide permethrin ( $250 \mathrm{~g}$ a.i/L) (Talcord $250 \mathrm{CE}$; BASF Corporation) applied at the rate of $200 \mathrm{~L} /$ ha.

\section{Fungicide treatments}

Two metconazole-based commercial fungicides, formulated either with metconazole ( $90 \mathrm{~g}$ a.i./L) (Caramba $90 \mathrm{EC}$; BASF Corporation) or in mixture with pyraclostrobin (metconazole $80 \mathrm{~g}$ a.i./L + pyraclostrobin $130 \mathrm{~g}$ a.i./L) (Opera Ultra EC; BASF Corporation) were tested. The metconazole fungicide was applied at the recommended dosage rate $(0.9 \mathrm{~L} / \mathrm{ha})$ and the mixture was tested in two dosage rates $(0.5$ and $0.75 \mathrm{~L} / \mathrm{ha})$. Each of those was tested both in a single spray at mid-flowering [Zadoks growth stage (ZGS) 64] and in two sequential sprays with the second spray applied ten days after the first spray. In total, seven treatments were tested: the six fungicide treatments and a non-sprayed check. Fungicides were applied at a rate of 200L/ha using a $\mathrm{CO}_{2}$ pressurized (200 $\mathrm{kPa}$ ) back-sprayer (Herbicat Ltda.) with four front plan spray nozzles (Jacto 1100.2 ) spaced $0.5 \mathrm{~m}$.

\section{Data collection}

At the pre-harvest period, two weeks after the second fungicide spray, 50 wheat heads were randomly collected at the three central rows of each plot and taken to the laboratory where visual assessments of FHB incidence (INC) (proportion of diseased heads in a sample) and conditional severity (CSEV) (proportion of diseased spikelets in a diseased wheat head) were made. FHB field severity (SEV, \%) (also known as FHB index) was calculated using the formula: $\mathrm{SEV}=(\mathrm{INC} \times \mathrm{CSEV}) \times 100$. Harvest was done manually in an area of $2.55 \mathrm{~m}^{2}$ in the experimental plots. Heads were threshed mechanically using a seed cleaning equipment. Three FHB-related variables were assessed in the harvested mature kernels: Fusarium-damaged kernels (FDK, \%), FIK (Fusariuminfected kernels, \%) and concentration of the trichothecene mycotoxins deoxynivalenol (DON) and nivalenol (NIV). Kernel infections were assessed using a standard blotter freezing seed-health test and FDK assessed visually. DON and NIV concentration were determined using a GC-MS/ 
MS method as described elsewhere (Del Ponte et al., 2012). Finally, subsamples were taken to assess three grain yield variables: thousand-seed weight (TGW, g); test weight (TW, kg/100L) and wheat grain yield (YLD, kg/ha). All disease and yield variables were assessed in each replicate. However, due to the high cost of mycotoxin analysis, a bulked sample was made with grain from all blocks of a same treatment prior to analysis.

\section{Meteorological conditions from flowering to harvest}

Minimum and maximum air temperature $\left({ }^{\circ} \mathrm{C}\right)$, relative humidity $(\%)$, rainfall $(\mathrm{mm})$, were recorded daily with INMET (Instituto Nacional de Meteorologia) weather stations (HydroMet MAWS301 model, Vaisala) located no more than $30 \mathrm{~km}$ from each trial. Flowering occurred at different times across the trials, following a west-east gradient (Figure 1). For example, in CA and PF peak
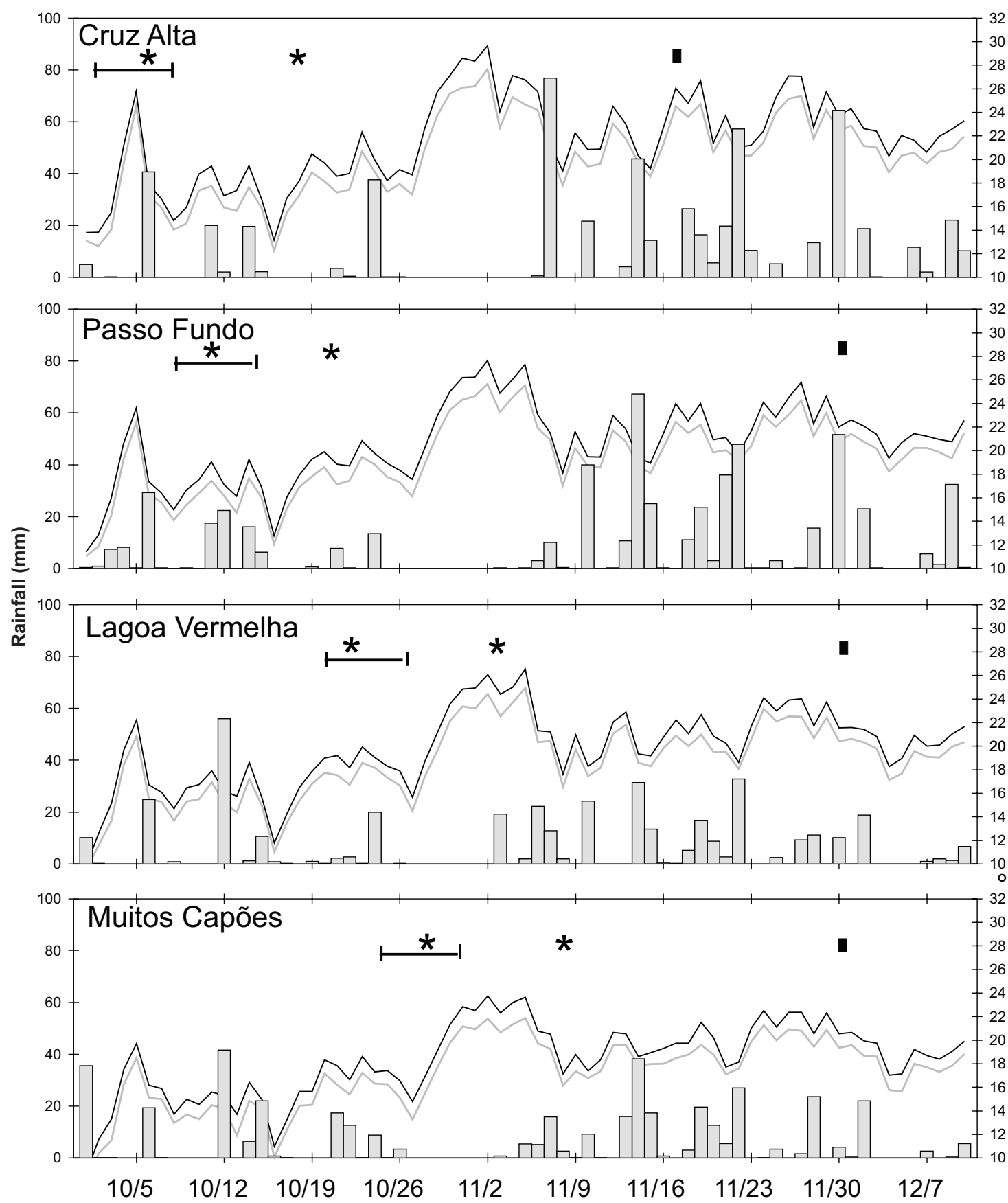

Calendar date

FIGURE 1 - Minimum and maximum air temperature $\left({ }^{\circ} \mathrm{C}\right)$, relative humidity $(\%)$, rainfall (mm) recorded daily in four field trials. * Fungicides spray; $|-|$ anthesis period; $\mathbf{a}$ harvest. 
flowering occurred in the first and second week of October, respectively, while in LV and $\mathrm{MC}$ trials, more towards east, flowering occurred in the third and fourth week of October. Meteorological conditions during the flowering and postflowering period differed among the locations. From early flowering to 10 days after the second spray, wetter and warmer conditions were observed following the same westeast gradient of flowering time in the trials. In CA and PF, in the four-week period after early flowering, only seven rain events were record and mean daily temperature was below $20^{\circ} \mathrm{C}$. Although rain events were more concentrated during the peak flowering period in $\mathrm{PF}$, cumulative rain was higher in CA for the 4-week period than in PF. For these two trials, a dry period longer than 10 consecutive days prevailed a week after the second spray, with a rise in the daily mean temperature peaking $26{ }^{\circ} \mathrm{C}$. This dry period was then followed by a very wet period in the two to three weeks prior to flowering, which delayed considerably harvesting operation in PF untill late November because of the 15 rain events recorded in that period. For the LV and MC trials, the number of rainy days from flowering up to 10 days after the second spray (grain filling) was 9 and 12, respectively, with five events of two-consecutive days of rain recorded in MC. These rain events were mainly concentrated in the post flowering period, especially in the MC trial where only one rain event was recorded during the peak flowering period. However, the month of November, prior to harvesting which was conducted in the last day of the month, was a very wet month with 17 and 19 rainy days in LV and MC. Mean daily temperature in these trials was higher than in the other two trials, mostly around $20^{\circ} \mathrm{C}$.

\section{Data analyses}

Data were analysed for each trial and also combined data from all trials using a mixed modeling approach. For the trial-based analysis, fungicide treatments were considered a fixed factor and blocks a random factor. The model was run using PROC MIXED (SAS Institute). A model using PROC MIXED METHOD=TYPE3 was run to assess the significance of fixed effect. In the combined analysis, the environments (location $\mathrm{x}$ cultivar) were considered to be a random factor. Fungicide treatments, cultivar resistance (S or MR) and cultivar $\mathrm{x}$ fungicide interaction were considered fixed effects, whereas block (location) was considered a random factor (Hollingsworth et al., 2008). Best linear unbiased estimate (BLUE) values were calculated for fixed effects with PROC MIXED Method=REML (Restricted or Residual maximum likelihood) because the distribution of the dependent variable (error term and the random effects) is normal. Treatment effects were analyzed using CONTRAST statement for the following comparisons: non-treated versus fungicide treated; one versus two fungicide spray; metconazole alone versus the mixture; and lower versus higher rate for the mixture. Cultivars were grouped in one of the two FHB resistance groups (S or MR). Mean estimate and BLUE values were used to determine the magnitude and direction of significance differences. For testing the treatments effects on mycotoxin data (DON, NIV and DON + NIV), in which no true replication was available for each treament within a trial, a linear model using PROC GLM was run and CONTRAST analysis for aforementioned groups in which trials were considered random effects.

\section{RESULTS AND DISCUSSION}

\section{Fungicide effect on disease variables}

All fungicide treatments had a significant effect $(\mathrm{P}<0.05)$ for at least three of the four disease variables and two of the three yield variables assessed in all trials. However, in MC trial all yield variables were not significantly influenced by the fungicide treatments (Table 1). Amongst the FHB variables, incidence (INC) and severity (SEV) were significantly affected by treatment in all locations while Fusarium-damaged kernels (FDK) in the $\mathrm{LV}$ and $\mathrm{MC}$ trials and kernel infection (KI) in $\mathrm{CA}$ and $\mathrm{PF}$ were not influenced by treatments (Table 1). As to the grain yield, a significant effect was observed for all variables in the CA and PF trials, while test weight (TW) did not differ among the fungicide treatments in the LV and MC. The non significant effect of treatments on yield (YLD) was observed only in the MC trial.

The means comparison within a trial showed that all fungicide treatments were capable of significantly

TABLE 1 - Analysis of variance (F values) in fungicide trials conducted in four municipalities of Brazil $(\mathrm{CA}=\mathrm{Cruz} \mathrm{Alta}, \mathrm{PF}=\mathrm{Passo}$ Fundo, LV = Lagoa Vermelha and MC = Muitos Capões) to determine the effect of fungicide applications on Fusarium head blight field incidence (INC), severity (SEV), Fusarium-damaged kernels (FDK), kernel infection (KI), one-thousand seed weight (TGW), test weight (TW) and yield (YLD) in spring wheat, 2009 year

\begin{tabular}{|c|c|c|c|c|c|c|c|}
\hline \multirow[t]{2}{*}{ Trial code } & \multicolumn{4}{|c|}{ Disease variables } & \multicolumn{3}{|c|}{ Yield variables } \\
\hline & $\begin{array}{l}\text { INC } \\
(\%)\end{array}$ & $\begin{array}{l}\text { SEV } \\
(\%)\end{array}$ & FDK $(\%)$ & KI (\%) & TGW (g) & TW (Kg) & $\underset{\left(\mathrm{kg} \mathrm{ha}^{-1}\right)}{\text { YLD }}$ \\
\hline $\mathrm{CA}$ & $16.9 * *$ & $22.9 * *$ & $4.8 * *$ & $0.3^{\mathrm{ns}}$ & $20.6 * *$ & $8.7 * *$ & $3.7 * *$ \\
\hline $\mathrm{PF}$ & $16.3^{* *}$ & $12.2 * *$ & $11.9^{* *}$ & $1.5^{\mathrm{ns}}$ & $3.6^{*}$ & $3.7^{*}$ & $7.7 * *$ \\
\hline LV & $53.6 * *$ & $18.9^{* *}$ & $0.6^{\mathrm{ns}}$ & $9.7 * *$ & $3.5^{*}$ & $3.8^{\mathrm{ns}}$ & $2.8^{*}$ \\
\hline $\mathrm{MC}$ & $36.7 * *$ & $106.2^{* *}$ & $0.5^{\mathrm{ns}}$ & $5.9^{* *}$ & $3.1^{\mathrm{ns}}$ & $2.1^{\mathrm{ns}}$ & $1.8^{\mathrm{ns}}$ \\
\hline
\end{tabular}


reducing INC and SEV compared with the non-sprayed check in all trials. This was most evident in the two trials where a susceptible cultivar was used. In these situations, where INC was higher than $70 \%$ and SEV higher than $10 \%$ in the non-sprayed check, the mean reduction in FHB incidence was $73.2 \%$ in LV (cv. Raízes) and $89.6 \%$ in MC (cv. Supera) trial and the mean reduction in FHB severity was $82.3 \%$ in the LV and $81.9 \%$ in the MC trial (Table 2). Although FDK was significantly reduced when fungicides were applied in the CA and PF trials, no fungicide was capable of reducing FDK levels in LV and MC trials where visual disease incidence and severity was highly suppressed by the fungicides. Contrastingly, FDK levels were highest in the PF trial where SEV levels were the lowest among the locations. With regards to KI levels, they were more significantly reduced $(>50 \%)$ in the MC trial where two sprays of fungicides were applied or when two sprays and single sprays of metconazole or the mixture at the highest dosage were used for any fungicide treatment and trial (Table 2).

FHB intensity was significantly affected by the interaction of fungicide treatment and genotype resistance (Table 4). The highest levels of disease control when using a fungicide treatment, e.g. percent reduction in FHB

TABLE 2 - Effect of fungicides on the mean Fusarium head blight (FHB) incidence (INC), severity (SEV), percentage of Fusariumdamaged kernels (FDK), and kernel infection $(\mathrm{KI})$ in fungicide trials conducted in four municipalities of Brazil $(\mathrm{CA}=\mathrm{Cruz} \mathrm{Alta}, \mathrm{PF}=$ Passo Fundo, LV = Lagoa Vermelha and MC = Muitos Capões). MET = metconazole; PYR = pyraclostrobin; mixture dose (L/ha) and spray number (one or two times). Disease control was calculated using the mean value for each treatment relatively to the mean value in the non-sprayed treament for incidence $\left(\mathrm{INC}_{\text {cont }}\right)$ and severity $\left(\mathrm{SEV}_{\text {cont }}\right)$

\begin{tabular}{|c|c|c|c|c|c|c|}
\hline \multirow{2}{*}{$\begin{array}{l}\text { Trial code / cultivar } \\
\text { Treatment }\end{array}$} & \multicolumn{6}{|c|}{ FHB variable $(\%)$} \\
\hline & INC & INC $_{\text {cont }}$ & SEV & SEV $_{\text {cont }}$ & FDK & $\mathbf{K I}$ \\
\hline \multicolumn{7}{|l|}{ CA / Campo Real cv. } \\
\hline Non-sprayed & 58.8 & & 7.3 & & 4.1 & 18.7 \\
\hline MET+PYR $0.5(1 \mathrm{x})$ & 50.0 & 15.0 & 6.5 & 11.0 & 2.9 & 23.1 \\
\hline MET+PYR $0.7(1 \mathrm{x})$ & 37.6 & 36.1 & 3.8 & 47.9 & 3.5 & 21.0 \\
\hline $\operatorname{MET}(1 \mathrm{x})$ & 31.3 & 46.8 & 2.7 & 63.0 & 2.6 & 22.0 \\
\hline MET+PYR $0.5(2 x)$ & 25.0 & 57.5 & 2.1 & 71.2 & 3.7 & 20.3 \\
\hline MET+PYR 0.7 (2x) & 23.8 & 59.5 & 2.1 & 71.2 & 2.9 & 21.5 \\
\hline $\operatorname{MET}(2 x)$ & 26.3 & 55.3 & 3.1 & 57.5 & 2.3 & 26.7 \\
\hline$L S D(P<0.05)$ & 15.4 & & 2.8 & & 0.9 & 10.1 \\
\hline \multicolumn{7}{|l|}{ PF / Guamirim cv. } \\
\hline Non-sprayed & 43.8 & & 5.0 & & 14.9 & 82.1 \\
\hline MET+PYR $0.5(1 \mathrm{x})$ & 23.9 & 45.4 & 2.1 & 58.0 & 13.3 & 79.3 \\
\hline MET+PYR 0.7 (1x) & 23.8 & 45.7 & 2.1 & 58.0 & 10.4 & 79.6 \\
\hline $\operatorname{MET}(1 \mathrm{x})$ & 26.3 & 66.5 & 2.3 & 54.0 & 8.6 & 84.1 \\
\hline MET+PYR $0.5(2 x)$ & 18.8 & 57.1 & 1.9 & 62.0 & 8.1 & 75.5 \\
\hline MET+PYR $0.7(2 x)$ & 10.0 & 77.2 & 0.9 & 82.0 & 8.1 & 83.6 \\
\hline $\operatorname{MET}(2 x)$ & 20.0 & 57.3 & 1.7 & 66.0 & 7.5 & 67.0 \\
\hline $\operatorname{LSD}(P<0.05)$ & 5.4 & & 1.0 & & 2.3 & 16.8 \\
\hline \multicolumn{7}{|l|}{ LV / Raízes cv. } \\
\hline Non-sprayed & 76.3 & & 10.1 & & 8.5 & 48.8 \\
\hline MET+PYR $0.5(1 \mathrm{x})$ & 21.3 & 72.1 & 1.8 & 82.2 & 11.9 & 22.5 \\
\hline MET+PYR 0.7 (1x) & 30.0 & 60.7 & 2.7 & 73.3 & 8.5 & 24.2 \\
\hline $\operatorname{MET}(1 \mathrm{x})$ & 31.3 & 59.0 & 3.6 & 64.4 & 11.5 & 12.5 \\
\hline MET+PYR $0.5(2 x)$ & 18.3 & 76.0 & 1.3 & 87.1 & 8.5 & 13.7 \\
\hline MET+PYR $0.7(2 x)$ & 8.8 & 88.5 & 0.4 & 96.0 & 10.3 & 18.0 \\
\hline $\operatorname{MET}(2 x)$ & 13.8 & 81.9 & 0.9 & 91.1 & 7.0 & 13.3 \\
\hline$L S D(P<0.05)$ & 9.0 & & 2.0 & & 4.0 & 8.9 \\
\hline \multicolumn{7}{|l|}{ MC / Supera cv. } \\
\hline Non-sprayed & 90.0 & & 31.3 & & 6.7 & 43.8 \\
\hline MET+PYR 0.5(1x) & 42.5 & 52.8 & 8.3 & 73.5 & 4.5 & 43.7 \\
\hline MET+PYR 0.7(1x) & 38.8 & 56.9 & 5.6 & 82.1 & 6.3 & 30.6 \\
\hline $\operatorname{MET}(1 \mathrm{x})$ & 46.3 & 48.6 & 7.1 & 77.3 & 5.5 & 23.5 \\
\hline MET+PYR 0.5(2x) & 42.5 & 52.8 & 5.7 & 81.8 & 6.3 & 27.8 \\
\hline MET+PYR 0.7(2x) & 25.0 & 72.2 & 2.4 & 92.3 & 5.6 & 23.1 \\
\hline $\operatorname{MET}(2 \mathrm{x})$ & 27.5 & 69.4 & 4.8 & 84.7 & 5.2 & 26.8 \\
\hline $\operatorname{LSD}(P<0.05)$ & 10.6 & & 4.9 & & 3.1 & 5.3 \\
\hline
\end{tabular}


severity related to the non-sprayed check, were observed for the susceptible genotypes $(>63 \%)$ and the lowest, but most variable, for the moderately resistant genotypes (1786\%). Mean FHB incidence percent control was lower than FHB severity control but in similar trend for the resistant genotypes (Figure 2). For all fungicide treatments, FHB severity control was highest for susceptible genotypes, but no clear effect of genotype resistance and fungicide efficacy was observed in FHB incidence control (Figure 3). For the FDK and KI variables, no significant effect was found for either fungicide treatment or genotype, with the exception of KI that was significantly influenced by the resistance level of the cultivar; mean kernel infection levels of 50.3\% in the moderately resistant and $26.1 \%$ in the susceptible cultivar were determined (Table 4).

The sub-group comparison for the FHB variables confirmed that fungicides significantly reduced FHB incidence, severity and kernel infection compared to the non-sprayed check, while not affecting FDK (Table 4). The one-versus-two-spray comparison showed significantly higher reduction only for kernel infection variable when using two sprays. While the lower versus higher dosage for the fungicide mixture treatments did not differ for any disease variable, the triazole versus mixture comparison showed the highest reduction in KI when using the triazole alone.

The FHB control levels we found, although apparently high, are within the variation found by a metaanalytical summary (Paul et al., 2008) and specifficaly agrees with a previous report from Brazil in which overall mean reduction of $43 \%$ in $\mathrm{FHB}$ incidence and $70 \%$ in
FHB severity were obtained using fungicides around flowering to control FHB using triazole alone (metconazole or tebuconazole) or in mixture with strobilurin fungicide (tryfloxistrobin + tebuconazole, azoxystrobin + ciproconazole or pyraclostrobin + epoxiconazole) (Casa et al., 2007). Yoshida et al. (2012) used two sequential sprays of thiophanate methyl which similarly to our study did not result in higher severity reduction despite the efficacy of FHB incidence reduction which ranged from $49 \%$ to $88 \%$ using sequential sprays of thiophanate methyl.

The fungicide efficacy seems to be dependent on the resistance level of the cultivar (Mesterházy et al., 2003; Wegulo et al., 2011; Willyerd et al., 2012), but results are contradictory in the literature. While highest reductions in FHB and mycotoxin levels were more likely when using varieties less susceptible to FHB (Mesterházy et al., 2003; Wegulo et al., 2011), other studies are in agreement with our findings in that highest FHB control was determined for the most susceptible varieties (Willyerd et al., 2012). The distinct experimental conditions and/or methodology such as the use of artificial inoculation and/or irrigation to promote high disease pressure may lead to these differences (Mesterházy et al., 2003; Hollingsworth et al., 2008; Wegulo et al., 2011). For example, in the work by Wegulo et al. (2011), FHB severity varied from 30 to $46 \%$ in the less susceptible and from 78 a $99 \%$ in the most susceptible varieties. Those values are much greater than the maximum severity of $7.3 \%$ and $31 \%$ found in our study for the less and most suscebtible varieties, respectively. When a decision for a suscetible variety is made, the use of fungicides may result in a greater relative reductions when compared to
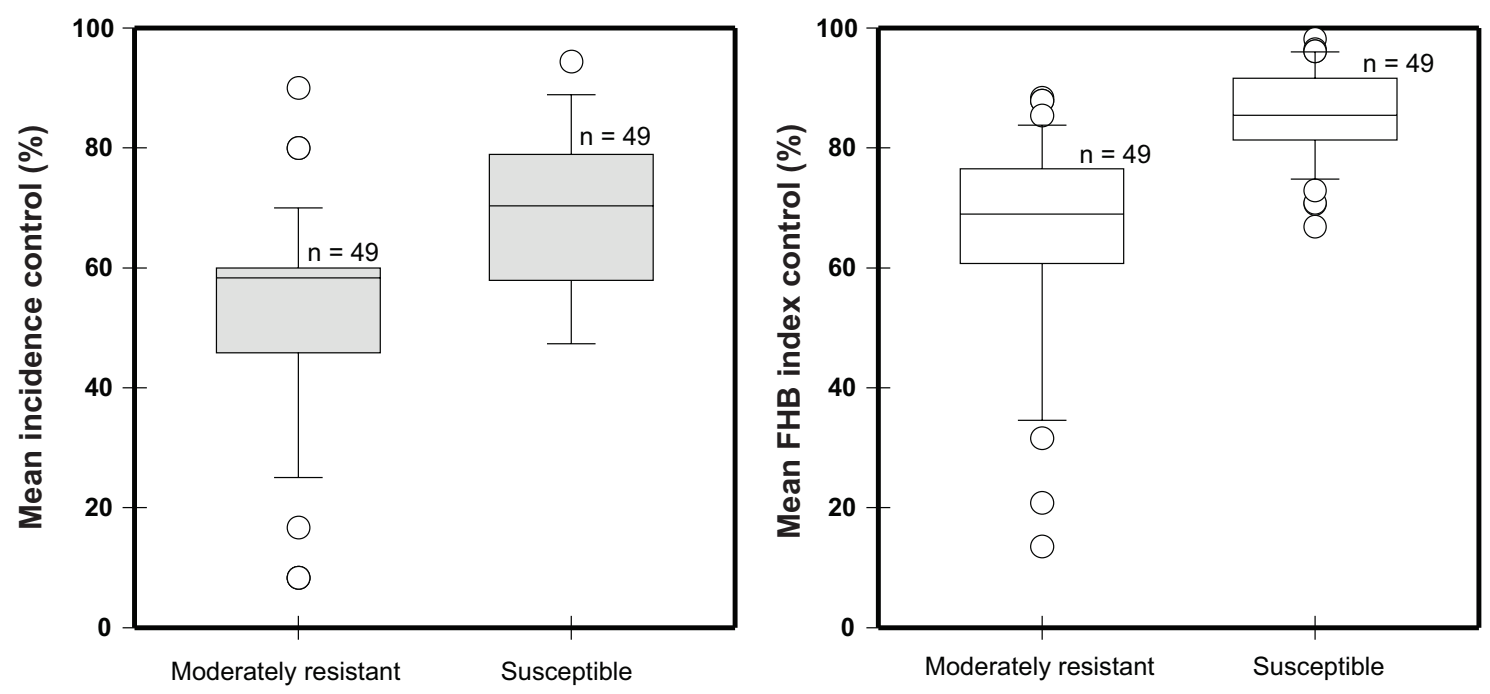

FIGURE 2 - Boxplots of Fusarium head blight (FHB) incidence and severity or index control (\% disease reduction related to the disease level in the check treatment) by fungicides tested in two wheat genotypes groups (moderately resistant and susceptible) averaged across four locations. Boxes indicate the median (solid line), 25 and 75 percentiles, respectively, vertical line shows the maximum and minimum, respectively, of the distribution and circles refer to outlying data points. 

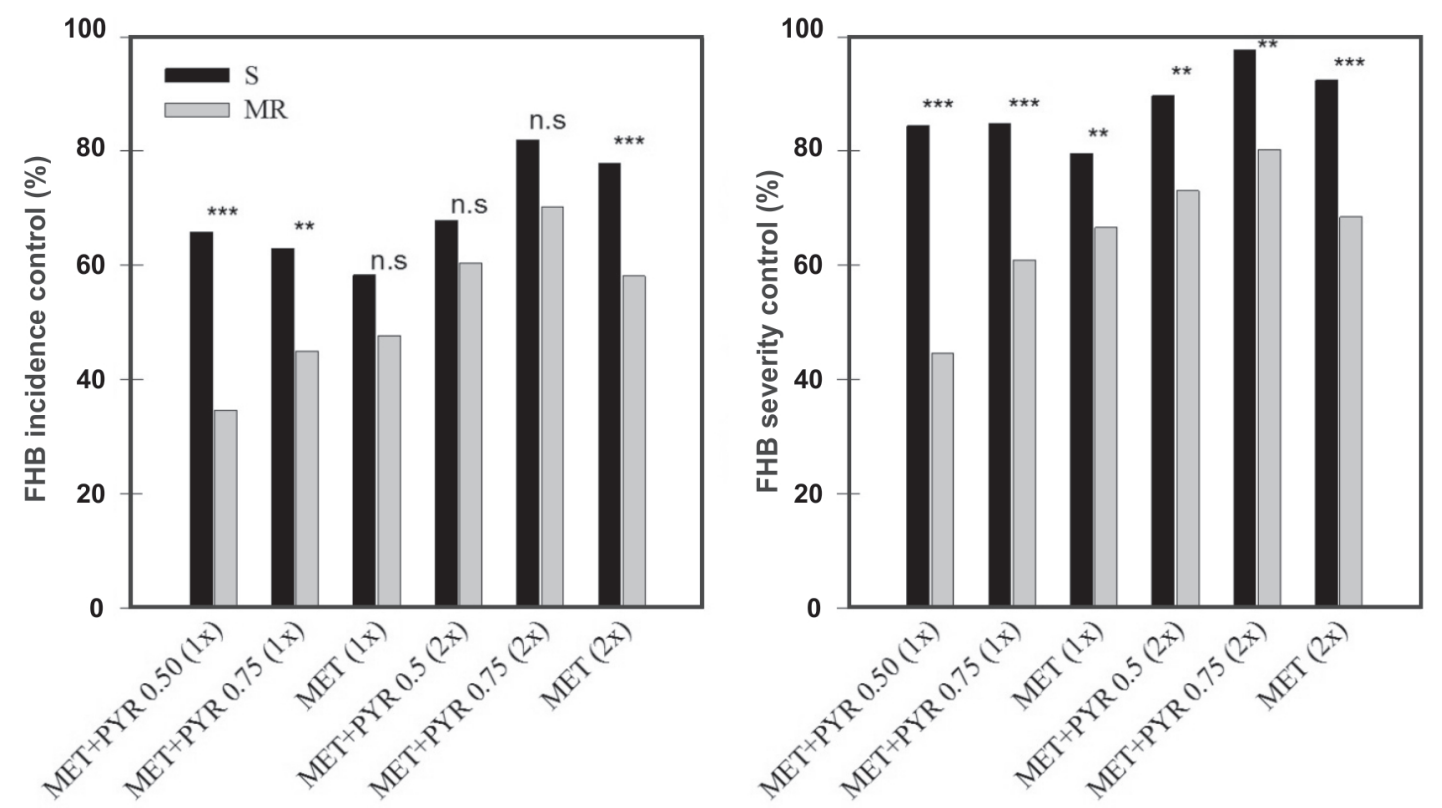

FIGURE 3 - Interaction effect of cultivar susceptibility to Fusarium head blight (FHB) and fungicide application - one or two sequential application of metconazole (MET) applied alone or in mixture with pyraclostrobin (PYR), in two dosages - on the control (mean \% disease reduction related to the disease level in the check treatment) of the disease incidence and severity. Columns with the $* *$ or $* * *$ means a signicant different between the susceptibility group according to the least significant difference (LSD) test at $P=0.01$ or $P=0.001$, respectively. $\mathrm{ns}=$ non significant differences for the contrast.

a resistant variety. Therefore, when a suscetible but more markeatable cultivar is used, fungicides may increase their importance in the disease management.

The effect of fungicides in reducing the level of Fusarium damaged in the kernels were also influenced by the resistance level of the cultivar and it was significantly reduced only when a moderately resistant variety was used. This is in agreement with a previous report (Mesterházy et al., 2003) and may be related to resistance to kernel damage enhancing FHB control with fungicides (Willyerd et al., 2012). We also found that damaged kernel levels were not associated with kernel infection level, thus suggesting that distinct conditions seemed to affect both variables in each trial. Our results shows that where a susceptible variety was tested in a wetter environment at post flowering (MC trial), kernel infection levels were significantly supressed by the use of fungicides. Conversely, where a moderately resistant cultivar was used where the environment was more favorable (rainy) around anthesis, kernel damage was significantly suppressed (CA and PF trial).

\section{Fungicide effects on grain yield variables}

One thousand seed weight (TGW) increased significantly in all fungicide treatments compared to the non-sprayed check in the CA trial, where TGW levels were the lowest $(23.7 \mathrm{~g})$ in the unsprayed check among the trials. In this location, the most significant increase in TGW (30.1 g) was obtained when two sprays of the fungicide mixture at the highest dosage were used (Table 3). In PF trial, the only significant increase in TGW related to the non-sprayed check was obtained with either one spray of the mixture at the highest dosage or two sprays of metconazole. This latter treatment also increased TGW in the LV trial in relation to the non-sprayed check. Test weight (TW) did not differ among the fungicide treatments in the CA and PF trials, where significant fungicide treatment effect was found. Finally, grain yield (YLD) was significantly higher in the CA and LV trials when a single spray of the mixture at the highest dosage was used (Table 3). In PF, yield was not different among the fungicide treatments. The least increase (by using single spray of the mixture at the highest dosage) was around 50\% compared to the non-sprayed check.

Results of the combined analysis for the grain yield variables showed that only seed weight did not increase with the use of fungicides, while a modest increase in test weight and more significant increase in the yield was found: $400 \mathrm{~kg} /$ ha in average was gained when using any of the fungicide treatments (Table 4). For the other comparisons, both seed weight and test weight did not differ for all constrasts. Nonetheless, yield increased significantly $(275 \mathrm{~kg} / \mathrm{ha}$ in average) when using the mixture of fungicides compared to metconazole alone and a less pronounced increase $(150 \mathrm{~kg} /$ ha) was found when using two sprays compared to single spray (Table 4). 
TABLE 3 - Effect of fungicides on mean 1000-grain weight (TWG), test weight (TW), yield (YLD) and yield increase for each treatment relatively to the mean yield in the non-sprayed check $\left(\mathrm{YLD}_{\text {inc }}\right)$ in four experimental fields. MET = metconazole; PYR = pyraclostrobin; mixture dose (L/ha) and sprays number (one or two)

\begin{tabular}{|c|c|c|c|c|}
\hline \multirow{2}{*}{$\begin{array}{l}\text { Trial/Cultivar } \\
\text { Treatment }\end{array}$} & \multicolumn{4}{|c|}{ Yield variables } \\
\hline & TGW (g) & TW (kg/100L) & YLD (kg/ha) & $Y_{L D}$ inc $(\%)$ \\
\hline \multicolumn{5}{|l|}{ CA /Campo Real cv. } \\
\hline Non-sprayed & 23.7 & 70.3 & 2764 & \\
\hline MET+PYR $0.5(1 \mathrm{x})$ & 28.8 & 74.4 & 3115 & 11.3 \\
\hline MET+PYR 0.7 (1x) & 28.6 & 75.5 & 3631 & 23.9 \\
\hline $\operatorname{MET}(1 \mathrm{x})$ & 27.2 & 75.0 & 2723 & -1.5 \\
\hline MET+PYR $0.5(2 x)$ & 28.0 & 75.5 & 2567 & -7.1 \\
\hline MET+PYR $0.7(2 \mathrm{x})$ & 30.1 & 75.5 & 2666 & -3.7 \\
\hline $\operatorname{MET}(2 x)$ & 27.8 & 75.4 & 3001 & 7.9 \\
\hline$L S D(P<0.05)$ & 0.7 & 2.1 & 455 & \\
\hline \multicolumn{5}{|l|}{ PF / Guamirim cv. } \\
\hline Non-sprayed & 33.1 & 64.7 & 1283 & \\
\hline MET+PYR $0.5(1 \mathrm{x})$ & 33.2 & 68.5 & 2837 & 54.7 \\
\hline MET+PYR 0.7 (1x) & 35.7 & 67.9 & 2396 & 46.5 \\
\hline $\operatorname{MET}(1 \mathrm{x})$ & 32.5 & 67.0 & 2445 & 47.5 \\
\hline MET+PYR $0.5(2 x)$ & 33.8 & 68.2 & 2935 & 56.3 \\
\hline MET+PYR $0.7(2 x)$ & 34.0 & 67.5 & 2649 & 51.6 \\
\hline $\operatorname{MET}(2 x)$ & 35.1 & 67.6 & 2567 & 50.0 \\
\hline$L S D(P<0.05)$ & 0.8 & 2.3 & 578 & \\
\hline \multicolumn{5}{|l|}{ LV / Raízes cv. } \\
\hline Non-sprayed & 23.2 & 70.4 & 1602 & \\
\hline MET+PYR $0.5(1 \mathrm{x})$ & 23.6 & 71.6 & 1954 & 18.0 \\
\hline MET+PYR $0.7(1 \mathrm{x})$ & 24.0 & 71.3 & 2379 & 32.7 \\
\hline $\operatorname{MET}(1 \mathrm{x})$ & 21.4 & 71.5 & 1253 & -27.9 \\
\hline MET+PYR $0.5(2 x)$ & 24.7 & 72.1 & 1889 & 15.2 \\
\hline MET+PYR $0.7(2 \mathrm{x})$ & 25.3 & 71.9 & 1570 & -2.0 \\
\hline $\operatorname{MET}(2 \mathrm{x})$ & 25.4 & 72.6 & 1447 & \\
\hline$L S D(P<0.05)$ & 1.2 & 2.3 & 670 & \\
\hline \multicolumn{5}{|l|}{ MC / Supera cv. } \\
\hline Non-sprayed & 30.3 & 70.6 & 2772 & \\
\hline MET+PYR 0.5(1x) & 29.3 & 70.9 & 2813 & 1.5 \\
\hline MET+PYR 0.7(1x) & 32.0 & 72.0 & 2919 & 5.0 \\
\hline $\operatorname{MET}(1 \mathrm{x})$ & 32.1 & 71.6 & 2573 & -7.7 \\
\hline MET+PYR 0.5(2x) & 31.7 & 71.7 & 2845 & 2.6 \\
\hline MET+PYR 0.7(2x) & 29.1 & 72.5 & 2709 & -2.3 \\
\hline $\operatorname{MET}(2 x)$ & 30.6 & 72.5 & 2802 & 1.1 \\
\hline$L S D(P<0.05)$ & 3.5 & 2.4 & 490 & \\
\hline
\end{tabular}

The overall mean relative yield increase we found $(10.7 \%)$ was similar to a report from Italy by Blandino et al. (2006) who discussed the beneficial effects of strobilurin due to a better control of leaf blotches and/or retarding foliar senescence (Blandino et al., 2011). We did not report the intensity levels of leaf blotch epidemics in our trials but the disease was present in variable levels across the trials, especially tan spot caused by Drechslera tritici-repentis, a reemergent and very common disease of non-tilled wheat in Brazil (Danelli et al., 2011). When mixed with triazole fungicides, pyraclostrobin may broaden the spectrum of protection (different modes of action) against other foliar diseases thus contributing to yield increase Although strobilurins applied alone are known to have lower or even non fungitoxic effects to FHB pathogens (Müllenborn et al., 2008; Dubos et al., 2011), Chen et al. (2012) showed that pyraclostrobin exhibited stronger inhibitory activity against mycelial growth of $F$. graminearum complex strains than that of epoxiconazole. Thus we may not rule out the effect of the fungicide mixture that led to most reductions in FHB variables in our study.

\section{Fungicides and mycotoxin contamination}

Both DON and NIV mycotoxins were found in all fungicide trials. There was no significant effect of individual fungicide treatment or sub-group comparison (contrast analysis, $P>0.05$ ) on DON, NIV neither DON+NIV concentration (Table 5), but the trials differed in the mean 
TABLE 4 - Summary of mean estimates and best linear unbieased estimates (BLUEs) from PROC MIXED analyses of four spring wheat cultivars grown in four locations in the southern Brazil in 2009 growing season exposed to seven fungicides treatments. Contrast differences significant at the $0.05(*)$ and $0.01(* *)$ levels

\begin{tabular}{|c|c|c|c|c|c|c|c|}
\hline \multirow{2}{*}{$\begin{array}{l}\text { Source of variation / } \\
\text { group mean }\end{array}$} & \multicolumn{4}{|c|}{ FHB variable } & \multicolumn{3}{|c|}{ Yield variable } \\
\hline & INC & SEV & FDK & KI & TGW & TW & YLD \\
\hline Fungicides (F) & 0.001 & $<0.001$ & 0.228 & 0.034 & 0.999 & 0.041 & 0.029 \\
\hline Non-treated check & $67.2 *$ & $13.6^{*}$ & 8.7 & $49.5^{*}$ & 27.8 & $68.9 *$ & $2139 *$ \\
\hline Fungicide treated & 27.5 & 3.2 & 6.8 & 36.9 & 29.4 & 71.61 & 2523 \\
\hline One-spray & $33.5^{*}$ & 7.3 & 7.3 & $39.5^{*}$ & 29.1 & 71.3 & $2304^{*}$ \\
\hline Two-spray & 21.5 & 6.0 & 6.0 & 34.5 & 29.7 & 71.9 & 2454 \\
\hline Triazole alone & 27.8 & 3.3 & 5.8 & $33.5^{*}$ & 29.1 & 71.3 & $2306^{*}$ \\
\hline Fungicide mixture & 27.4 & 3.1 & 7.1 & 38.6 & 29.6 & 71.7 & 2581 \\
\hline Mixture lower rate & $30.1^{*}$ & $3.7^{*}$ & $7.4^{* *}$ & $38.1^{*}$ & 29.1 & 71.6 & 2633 \\
\hline Mixture higher rate & 24.7 & 2.5 & 6.8 & 39.1 & 30.0 & 71.8 & 2542 \\
\hline Cultivar (C) & $<0.001$ & $<0.001$ & 0.428 & $<0.001$ & $<0.001$ & 0.521 & 0.003 \\
\hline Moderately resistant & 29.9 & 3.1 & 6.7 & 50.3 & 30.8 & 70.9 & 2684 \\
\hline Susceptible & 36.5 & 6.1 & 7.3 & 26.1 & 27.5 & 71.5 & 2247 \\
\hline F $\times C$ & $<0.001$ & $<0.001$ & 0.930 & 0.945 & 0.999 & 0.987 & 0.344 \\
\hline
\end{tabular}

mycotoxin concentration and the DON/NIV ratio (Figure 4 ). While DON was the most prevalent $(>95 \%$ of the total trichothecenes) toxin in the CA and PF trials, NIV was most prevalent in LV (>60\%) and MC (>95\%) (Figure 4). DON levels were higher in average than NIV, with the highest DON level found in the PF trial where it reached the 2.0 ppm threshold level in average (Figure 4). It is well know from the literature that the relationship between FHB and mycotoxin control is not consistent and seem to be very dependent on a complex interaction of biological and envrionmental factors. In the United States, fungicides were much more effective in reducing FHB intensity than the DON levels (Paul et al., 2007). It has been suggested that the conditions favorable for the disease and deoxynivalenol accumulation may be distinct and uncoupled, especially under field conditions (Gautam and Dill-Macky, 2011).

Most studies on the use of strobilurins for FHB control have focused on azoxystrobin and this is the first report on the efficacy of a pyraclostrobin+metconazole mixture in South American wheat-growing regions. Recently, in North America, a commercial mixture of metconazole + pyraclostrobin (TwinLine ${ }^{\circledR}$ BASF Corporation) was tested in single spray before flowering and caused an increase of DON compared to the non-treated control in only one out of several locations (Bradley et al., 2011). However, such increase associated with a single pyraclostrobin (Headline) application at Feekes 9 (ligule of flag leaf visible) in that study generally was negated when that treatment was subsequently followed by an application of a triazole fungicide (metconazole or prothioconazole plus tebuconazole) at Feekes 10.5.1 (beginning flowering).
In our study, the absence of reduction in the mycotoxin levels with the use of fungicides (Table 5), among other factors, may be related to the relatively low mycotoxin levels, in spite of the relatively high disease severity in one of the trials. In the United States, the mean DON reduction by the use of fungicides increased $28 \%$ when DON levels

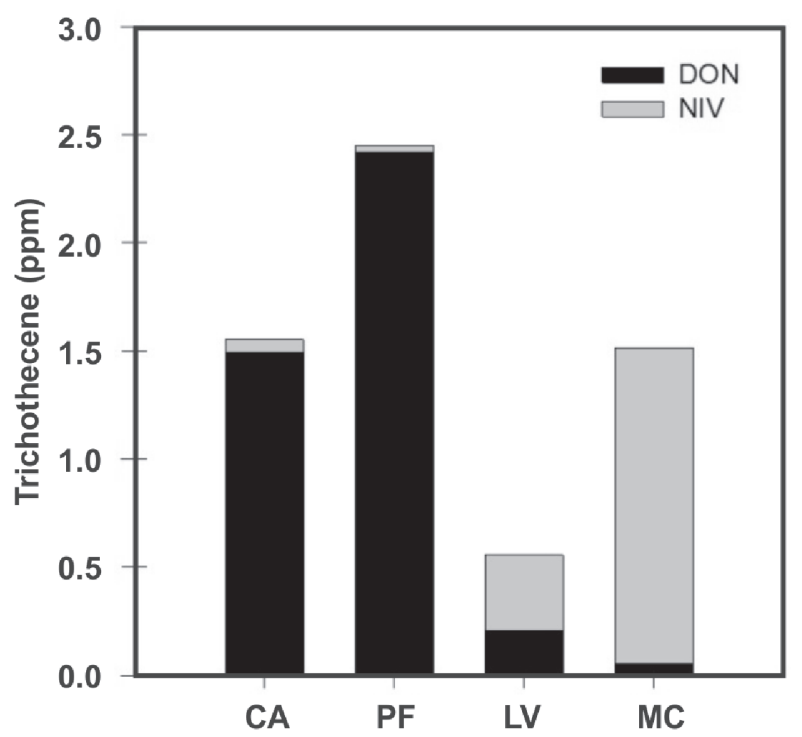

FIGURE 4 - Deoxynivalenol (DON) and nivalenol (NIV) overall mean concentration in wheat grain across all treatments in fungicide trials conducted at four locations in southen Brazil: CA $=$ Cruz Alta; $\mathrm{PF}=$ Passo Fundo; $\mathrm{LV}=$ Lagoa Vermelha and $\mathrm{MC}=$ Muitos Capões. 
TABLE 5 - Effect of fungicide treaments on the overall mean concentration of deoxynivalenol (DON), nivalenol (NIV) and total concentration of trichotechenes (DON + NIV) in wheat grains from fungicide trials conducted at four locations in southern of Brazil, season 2009. $\mathrm{MET}=$ metconazole; $\mathrm{PYR}=$ pyraclostrobin; mixture dosage $(\mathrm{L} / \mathrm{ha})$ and spray number (one or two)

\begin{tabular}{lccc}
\hline \hline Treatment & \multicolumn{3}{c}{ Overall mean concentration (ppm) } \\
\cline { 2 - 4 } & DON & NIV & 0.8 \\
\hline Non-sprayed & 0.5 & 0.3 & 2.0 \\
MET+PYR 0.5 (1x) & 1.7 & 0.3 & 2.5 \\
MET+PYR 0.7 (1x) & 2.1 & 0.4 & 1.6 \\
MET (1x) & 1.3 & 0.3 & 1.3 \\
MET+PYR 0.5 (2x) & 1.0 & 0.4 & 1.2 \\
MET+PYR 0.7 (2x) & 0.4 & 0.8 & 1.3 \\
MET (2x) & 0.4 & 0.9 & 1.8 \\
\hline LSD $(P<0.05)$ & 1.7 & 0.7 & 2 \\
\hline
\end{tabular}

in the kernels were between 1 and $10 \mathrm{ppm}$ and was much lower than when DON is $<1 \mathrm{ppm}$ (Paul et al., 2007). The overall mean trichothecene (DON + NIV) levels of 0.5 ppm we found across the trials can be considered very low compared to the $11 \mathrm{ppm}$ found in the study by Edwards et al. (2011). In our case, the fact that distinct trichothecenes were found in our trials does not allow a direct comparison with other studies because most studies focus on DON, likely because of the current regulations for DON and not NIV or the absence of this latter toxin in some regions. In the study by Nakajima (2007) in Japan, where both DON and NIV toxins are usually found, in experiments when a mix of DON and NIV-producers were inoculated, the azoxystrobin+propiconazole mixture did not affect the total trichothecenes in the grains, which is in agreement with our findings using the mixture.

Because different trichothecenes were prevalent across the trials, we hypothesize that distinct populations may have prevailed across the trials, since regional populations of $F$. graminearum in RS State are composed by both DON- and NIV-producers (Astolfi et al., 2012) and co-contamination was found in commercial wheat grain (Del Ponte et al., 2012). Because agressiveness seems to differ between these two regional populations according to resistance level of the variety (Spolti et al., 2012), it is likely that a complex interaction among several factors affected fungicide efficacy by a diferent way for the disease variables when in comparison to the type and amount of trichothecene found predominantly. It will be instructive to further assess fungicide efficacy under a scenario of multiple species with varying toxigenic potential and higher disease pressure, especially targeting mycotoxin reduction.

In conclusion, metconazole alone or in mixture with pyraclostrobin can effectively reduce FHB impact at both pre- and post-harvest and lead to increased yield when using an additional spray at post flowering period when a susceptible variety is used. The decision to use sequential sprays on wheat around flowering should also take economic factors into account. Considering a scenario of the wheat price in Rio Grande do Sul State (U\$ 296/ton) and the increase in yield $(275 \mathrm{~kg} / \mathrm{ha})$ found in our study when using the mixture of fungicides, application costs with the mixture of fungicides should cost less than U\$ 81,00/ha for an economic return. For sequential applications considering the same economic scenario but with a mean increase of $150 \mathrm{~kg} /$ ha in yield, application costs should be less than U\$44,00/ ha. These economic scenarios are an oversimplification because there are others grain quality parameters that can influence the final wheat price. Moreover the scenarios tend to be more complex if grain will be discounted for mycotoxin accumulation (Hollingsworth et al., 2008). Additional studies under conditions more favorable for disease and mycotoxin development will be necessary in order to verify whether application of fungicide mixtures can effectivelly contribute to better yields and grain quality with mycotoxin levels below the maximum limits.

\section{ACKNOWLEDGEMENTS}

Authors are grateful to Gary C. Bergstrom (Cornell University) for critically reviewing the manuscript. Thanks are also given to Juliano dos Santos, Liara L. Simon, and Lucas Navarini for field work assistance and to wheat growers for providing area for the experiments. First and fourth authors are thankful to Conselho Nacional de Desenvolvimento Científico e Tecnológico - CNPq for the research scholarship and a research fellowship, respectively.

\section{REFERENCES}

Astolfi P, Reynoso MM, Ramirez ML, Chulze SN, Alves TCA, Tessmann DJ, Del Ponte EM (2012) Genetic population structure and trichothecene genotypes of Fusarium graminearum isolated from wheat in southern Brazil. Plant Pathology 61:289-295.

Blandino M, Minelli L, ReyneriA(2006) Strategies for the chemical control of Fusarium head blight effect on yeld, alveographic parameters and deoxynivalenol contaminations in winter wheat grain. European Journal of Agronomy 25:193-201.

Blandino M, Pascale M, Haidukowski M, Reyneri (2011) Influence 
Single and sequential applications of metconazole alone or in mixture with pyraclostrobin...

of agronomic conditions on the efficacy of different fungicides applied to wheat at heading: effect on flag leaf senescence, Fusarium head blight attack, grain yield and deoxynivalenol contamination. Italian Journal of Agronomy 6:204-211.

Bradley CA, Adee EA, Ebelhar, SA, Bergstrom GC, Dill-Macky R, Wiersma JJ, Grybauskas AP, Kirk WW, McMullen MP, Halley S, Milus EA, Osborne LE, Ruden KR, Wise KA, Conley SP, Esker PD (2011) Uniform Fungicide Tests 2011: Effects of triazole and strobilurin fungicides on Fusarium head blight and associated mycotoxins. Research update to the US wheat and barley scab initiative. Available at: scabusa.org/pdfs_dbupload/ USWBSI_2011-Report_Uniform-IM.pdf. Accessed on December 20, 2011.

Brasil (2011) Regulamento técnico sobre limites máximos tolerados (LMT) para micotoxinas em alimentos. Resolução RDC $\mathrm{n}^{\mathrm{o}} 7$, de 18 de fevereiro de 2011. Brasília DF. Anvisa. Available at: www.brasilsus.com.br/legislacoes/rdc/107502-7.html. Accessed on October 03, 2011.

Casa RT, Bogo A, Moreira EN, Kuhnem Junior PR (2007) Época de aplicação e desempenho de fungicidas no controle da giberela em trigo. Ciência Rural 37:1558-1563.

Chen Y, Zhang A-F, Gao T-C, Zhang Y, Wang W-X, Ding K-J, Chen L, Sun Z, Fang X-Z, Zhou M-G (2012) Integrated use of pyraclostrobin and epoxiconazole for the control of Fusarium head blight of wheat in Anhui Province of China. Plant Disease 96:1495-1500.

Cowger C, Patton-Özkurt J, Brown-Guedira G, Perugini L (2009) Post-anthesis moisture increased Fusarium head blight and deoxynivalenol levels in North Carolina winter wheat. Phytopathology 99:320-327.

Cowger C, Arrellano C (2010) Plump kernels with high deoxynivalenol linked to late Gibberella zeae infection and marginal disease conditions in winter wheat. Phytopathology 100:719-728.

Danelli ALD, Reis EM, Fiallos RFG (2011) Etiologia e intensidade de manchas foliares em cultivares de trigo em três locais do Rio Grande do Sul, Brasil. Scientia Agropecuaria 2:149-155.

Del Ponte EM, Fernandes JMC, Pavan W, Pierobom CR (2004) Simulação da dinâmica do florescimento do trigo como base para um modelo de risco de giberela . Revista Brasileira de Agrociência 10:323-331.

Del Ponte EM, Fernandes JMC, Bergstrom GC (2007) Influence of growth stage on Fusarium head blight and deoxynivalenol production in wheat. Journal of Phytopathology 155:577-581.

Del Ponte EM, Fernandes JMC, Pavan W, Baethgen WE (2009) A model-based assessment of the impacts of climate variability on Fusarium head blight seasonal risk in southern Brazil. Journal of Phytopathology 157:675-681.

Del Ponte EM, Garda-Buffon J, Badiale-Furlong (2012) Deoxynivalenol and nivalenol in comercial wheat grain related to Fusarium head blight epidemics in southern Brazil. Food Chemistry 132:1087-1091.

Dubos T, Pasquali M, Pogoda F, Hoffmann L, Beyer M (2011) Evidence for natural resistance towards trifloxystrobin in Fusarium graminearum. European Journal of Plant Pathology 130:239-248.

Edwards SG, Pirgozliev SR, Hare MC, Jenkinson P (2001) Quantification of trichothecene-producing Fusarium species in harvested grain by competitive PCR to determine efficacies of fungicides against Fusarium head blight of winter wheat. Applied and Environmental Microbiology 67:1575-1580.

Gautam P, Dill-Macky R (2011) Impact of moisture, host genetics and Fusarium graminearum isolates on Fusarium head blight development and trichothecene accumulation in spring wheat. Mycotoxin Research 28:45-48.

Goswami RS, Kistler HC (2004) Heading for disaster: Fusarium graminearum on cereal crops. Molecular Plant Pathology 5:515525.

Hollingsworth CR, Motteberg CD, Wiersma JV, Atkinson LM (2008) Agronomic and economic responses of spring wheat to management of Fusarium head blight. Plant Disease 92:13391348.

Horevaj P, Gale LR, Milus EA (2011) Resistance in winter wheat lines to initial infection and spread within spikes by deoxynivalenol and nivalenol chemotypes of Fusarium graminearum. Plant Disease 95:31-37.

Mesterházy Á, Bartók T, Lamper C (2003) Influence of wheat cultivar, species of Fusarium, and isolate aggressiveness on the efficacy of fungicides for control of Fusarium head blight. Plant Disease 87:1107-1115.

Mesterházy A, Tóth B, Varga M, Bartók T, Szabó-Hevér A, Farády L, Lehoczki-Krsjak S (2011) Role of fungicides, application of nozzle types, and the resistance level of wheat varieties in the control of fusarium head blight and deoxynivalenol. Toxins 3:1453-1483.

Müllenborn C, Steiner U, Ludwig M, Oerke EC (2008) Effect of fungicides on the complex of Fusarium species and saprophytic fungi colonizing wheat kernels. European Journal of Plant Pathology 120:157-166.

Nakajima T (2007) Progress and outlook for the control of nivalenol and deoxynivalenol contamination due to Fusarium head blight in wheat. Mycotoxins 57:129-134.

Paul PA, Lipps PE, Hershman DE, McMullen MP, Draper MA, Madden LV (2007) A quantitative review of tebuconazole effect on Fusarium head blight and deoxynivalenol content in wheat. Phytopathology 97:211-220.

Paul PA, Lipps PE, Hershman DE, McMullen MP, Draper MA, Madden LV (2008) Efficacy of triazole-based fungicides for Fusarium head blight and deoxynivalenol control in wheat: a multivariate meta-analysis. Phytopathology 98:999-1011.

Paul PA, McMullen MP, Hershman DE, Madden LV (2010) Metaanalysis of the effects of triazole-based fungicides on wheat yield and test weight as influenced by Fusarium head blight intensity. Phytopathology 100:160-171.

Pirgozliev SR, Edwards SG, Hare MC, Jenkinson P (2002) Effect of dose rate of azoxystrobin and metconazole on the development of Fusarium head blight and the accumulation of deoxynivalenol (DON) in wheat grain. European Journal of Plant Pathology 108:469-478.

Ransom J, McMullen M (2008) Yield and disease control on hard winter wheat cultivars with foliar fungicides. Agronomy Journal 100:1130-1137.

Sarver BJ, Ward TJ, Gale LR, Broz K, Kistler HC, Aoki T, Nicholson P, Carter J, O’Donnell K (2011) Novel Fusarium head blight pathogens from Nepal and Louisiana revealed by multilocus 
genealogical concordance. Fungal Genetics and Biology 48:1096107.

Spolti P, Barros NC, Gomes LB, Santos J, Del Ponte EM (2012) Phenotypic and pathogenic traits of two species of the Fusarium graminearum complex possessing either 15-ADON or NIV genotype. European Journal of Plant Pathology 133:621-629.

Wegulo SN, Bockus WW, Hernandez Nopsa J, De Wolf ED, Eskridge KM, Peiris KHS, Dowell FE (2011) Effects of integrating cultivar resistance and fungicide application on Fusarium head blight and deoxynivalenol in winter wheat. Plant Disease 95:554560 .

Willyerd KT, Li C, Madden LV, Bradley CA, Bergstrom GC, Sweets LE, McMullen M, Ransom JK, Grybauskas A, Osborne L,
Wegulo SN, Hershman DE, Wise K, Bockus WW, Groth D, DillMacky R, Milus E, Esker PD, Waxman KD, Adee EA, Ebelhar SE, Young BG, Paul, PA (2012) Efficacy and stability of integrating fungicide and cultivar resistance to manage Fusarium head blight and deoxynivalenol in wheat. Plant Disease 96:957-967.

Yoshida M, Nakajima T (2010) Deoxynivalenol and nivalenol accumulation in wheat infected with Fusarium graminearum during grain development. Phytopathology 100:763-773.

Yoshida M, Nakajima T, Tomimura T, Suzuki F, Arai M, Miyasaka A (2012) Effect of the timing of fungicide application on Fusarium head blight and mycotoxin contamination in wheat. Plant Disease 96:845-851.

TPP-2012-0070 - Received 8 August 2012 - Accepted 3 November 2012 Section Editor: Marciel J. Stadnik 